\title{
Improving the Properties of Soft Soils using Nano-silica, Slag, and Cement
}

\author{
A. Eissa ${ }^{1}$, A. Ghazy ${ }^{2}$, M. T. Bassuoni ${ }^{3 *}$, and M. Alfaro ${ }^{4}$ \\ ${ }^{1}$ Ph.D. candidate, Department of Civil Engineering, University of Manitoba, Winnipeg, MB, Canada and Assistant \\ lecturer, Department of Structural Engineering, Tanta University, Tanta, Egypt \\ ${ }^{2}$ Adjunct Professor, Department of Civil Engineering, University of Manitoba, Winnipeg, MB, Canada, and \\ Department of Civil Engineering, University of Alexandria, Egypt \\ 3*Professor, Cementitious Materials, Department of Civil Engineering, University of Manitoba, Winnipeg, MB, \\ Canada (Corresponding author: mohamed.bassuoni@umanitoba.ca) \\ ${ }^{4}$ Professor, Geotechnical Engineering, Department of Civil Engineering, University of Manitoba, Winnipeg, MB, \\ Canada
}

\begin{abstract}
Effective utilization of weak soils such as soft clay by imparting additional strength using various stabilization techniques are adopted to enhance the soil behaviour (i.e., bearing capacity) for the construction of roads and/or platforms. Applications of nanomaterials in the field of geotechnical engineering have great potential, for example by promoting the construction of a stronger and stiffer soil skeleton, especially when blended with cementitious materials. Therefore, this paper focuses on studying the effect of nanomodified cementitious binders on the properties of weak soils, which are the most common types of soil in Winnipeg, Manitoba, Canada. The soil selected was soft clay. It was mixed with GU (general use) cement, or slag, or both with different proportions of nano-silica sol ( 0 to $2.4 \%$ of the dried soil weight). The mechanical properties such as the compressive strength at different curing ages and California bearing ratio (CBR) were investigated. Generally, the addition of nano-silica to cement enhanced the properties of the soil in terms of maximum dry density, compressive strength, and CBR. In particular, the bearing ratio for the soil treated with the ternary binder (cement, slag, and nano-silica) was improved. Thus, nano-modified blended cement presents a sustainable and effective stabilizing additive to treat weak soils for the construction of roads with an anticipated measurable impact on reducing the life-cycle cost of repairs due to its projected stability and durability.
\end{abstract}

Keywords: Soil Stabilization; Nano-silica; Slag Cement, Unconfined Strength, California bearing ratio

\section{Introduction}

Pavements constructed on soft soils can encounter many engineering problems such as low bearing capacity and movement. Stabilization techniques are adopted to enhance soft soil behaviour and performance. Chemical stabilization is widely used to mitigate this problem within a short period of time. Different categories of chemical additives have pronounced effects on changing the mechanical properties of soft clays or silts. Additives such as lime and gypsum have been used, but some issues related to durability aspects have been reported. For instance, soils stabilized with gypsum were not able to survive weathering conditions [1]. Thus, proper selection of the additive used is crucial for the success of this method, based on short- and long-term performance.

Portland cement is considered an efficient and economic additive for providing adequate strength for weak soils within days, in addition to satisfactory durability. The most common cement types used in technical literature are general use portland cement (GU cement) and blended cements comprising GU cement with fly ash or slag. Stabilizing soils with cement can improve subgrade properties at a lower cost than either removing and replacing weak layers or increasing the base and sub-base thicknesses to reduce subgrade stress. Besides the type of binder used, its content and water-to-binder ratio have significant effects on the durability of treated soil. The soil stabilization mechanism of calcium silicate-based additives such as GU and blended cements modifies soil properties through cation exchange, hydration reactions, agglomeration, and pozzolanic reaction. In particular, cement-based binders produce hydration products, which increase the strength and binding of subgrade materials and thus enhancing the permanence of the treated mixture [2]. 
Recently, it has been shown that nano-materials have promising effects at improving the engineering properties of powdered materials (i.e., clay, cement). For instance, nanoparticles (nano-silica) can enhance the performance of lowdensity materials, achieving small intergranular spaces to further interact with the matrix [3]. Also, nano-silica has been proven to significantly enhance the fresh, mechanical and durability properties of cement-based materials, comprising GU or blended cements [e.g. 4]; thus, it has a high potential to further enhance the performance of cement-based treated soils. However, very limited research has been done in this direction, which warrants further research to identify the optimum proportions of nano-modified cementitious materials that can enhance the properties of different soil types.

Given the aforementioned research needs, the current study focused on providing a fundamental understanding of the performance of treated soils with cementitious materials and nanoparticles. The treatments were done to the most common type of soil in Winnipeg to identify the optimum nano-modified cementitious binders to treat this soil.

\section{Methodology}

\subsection{Materials and Mixtures}

General Use cement and slag, which meet the requirements of CAN/CSA-A3001 standard [5], were used as the main components of the additives. Also, a commercial nano-silica sol with 50\% solid content of $\mathrm{SiO}_{2}$ particles dispersed in an aqueous solution of water and dispersing agents were used. Their physical and chemical properties are shown in Table 1. Sixteen soil-stabilized mixtures were prepared and a high-range water-reducing admixture (HRWRA) based on polycarboxylic acid and complying with ASTM C494-15 [6] Type F was added at dosages in the range of 50-200 ml/100 $\mathrm{kg}$ of the dried soil to maintain a workable mixture. This HRWRA is based on polycarboxylic acid and following ASTM C494-15 [6]. The soil sample collected from Winnipeg, Manitoba, Canada was used in this study. The soil was sampled from 0.8 to $1.2 \mathrm{~m}$ below the ground surface to present the sub-grade layer. According to the unified soil classification system (USCS) following ASTM D2487-17 [7] and ASTM D7928-17 [8], the soil is classified as high plasticity clay. Table 2 shows the soil properties including grain size distribution, Atterberg limits, water content, and specific gravity. Sixteen soil-stabilized mixtures shown in Table 3 were prepared to investigate the targeted parameters that are considered influential towards the properties of soil stabilized mix. The mix ID is composed of letters and numbers. The letter refers to the additive such as GU cement $(\mathrm{C})$, slag $(\mathrm{S})$, and nano-silica $(\mathrm{N})$, while the number after each letter indicates the additive's percentages related to the dried soil weight, and the last number indicates the water-to-solid ratio $(w / s)$ in the mix.

The control mixtures were prepared from $100 \%$ soil, representing reference sub-grade materials. GU cement and slag were used to prepare either single ( $20 \%$ by the soil's dry weight) or binary blended soil ( $40 \%$ by the soil's dry weight). The nano-silica was added at a dosage of $2.4 \%$ by the soil's dry weight to prepare single blended soil (comprising soil and nano-silica), binary blended soil (comprising either GU cement or slag and nano-silica) and ternary blended soil (comprising GU cement, slag, and nano-silica). Table 3 shows the mixture design proportions of the treated soil in this study. 
Table 1: Physical and chemical properties of GU cement, slag, and nano-silica.

\begin{tabular}{lccc}
\hline \multicolumn{1}{c}{ Composition/Property } & GU Cement & Slag & Nano-silica \\
\hline Chemical composition & & & \\
$\mathrm{SiO}_{2}(\%)$ & 19.21 & 33.40 & 99.17 \\
$\mathrm{Al}_{2} \mathrm{O}_{3}(\%)$ & 5.01 & 13.40 & 0.39 \\
$\mathrm{Fe}_{2} \mathrm{O}_{3}(\%)$ & 2.33 & 0.76 & 0.02 \\
$\mathrm{CaO}(\%)$ & 63.22 & 42.70 & -- \\
$\mathrm{MgO}(\%)$ & 3.31 & 5.30 & 0.21 \\
$\mathrm{SO}_{3}(\%)$ & 3.01 & 2.40 & -- \\
$\mathrm{Na}_{2} \mathrm{O}_{\text {eq. }}(\%)$ & 0.12 & 0.30 & 0.20 \\
$\mathrm{Physical} \mathrm{properties}$ & & & \\
$\mathrm{Specific}$ gravity & 3.15 & 2.87 & 1.40 \\
Mean particle size $(\mu \mathrm{m})$ & 13.15 & 11.45 & $35 \times 10^{-3}$ \\
Fineness, (m $\left.{ }^{2} / \mathrm{kg}\right)$ & $390^{\mathrm{a}}$ & $492^{\mathrm{a}}$ & $80,000^{\mathrm{b}}$ \\
\hline${ }^{\mathrm{a}} \mathrm{Blaine}$ fineness. & & \\
${ }^{\mathrm{b}}$ Fineness was determined by titration with sodium hydroxide. &
\end{tabular}

Table 2: Properties of the soil.

\begin{tabular}{lcc}
\hline \multicolumn{1}{c}{ Properties } & Value & Standard \\
\hline Silt content $(\%)$ & 27 & ASTM D7928-17 [8] \\
Clay content $(\%)$ & 70 & ASTM D7928-17 [8] \\
Natural water content $(\%)$ & 43 & ASTM D2216-19 [9] \\
Liquid limit $(\%)$ & 64 & ASTM D4318-17 [10] \\
Plastic limit $(\%)$ & 32 & ASTM D4318-17 [10] \\
Plasticity index $(\%)$ & 32 & ASTM D4318-17 [10] \\
Liquidity index $(\%)$ & 36 & ASTM D4318-17 [10] \\
Specific gravity & 2.57 & ASTM D854-14 [11] \\
Maximum dry density $\left(\mathrm{kN} / \mathrm{m}^{3}\right)$ & 15 & ASTM D698-12 [12] \\
Optimum moisture content $(\mathrm{OMC})(\%)$ & 17 & ASTM D698-12 [12] \\
California Bearing Ratio $(\mathrm{CBR})$ at OMC $(\%)$ & 5.5 & ASTM D1883-16 [13] \\
\hline
\end{tabular}


Table 3: Proportions of mixtures.

\begin{tabular}{lccc}
\hline \multicolumn{1}{c}{ Mixture ID. } & Cement \% & Slag \% & Nano-silica \% \\
\hline w/s $=53 \%$ & & & \\
Control-53 & 0 & 0 & 0 \\
C20-53 & 20 & 0 & 0 \\
S20-53 & 0 & 20 & 0 \\
N2.4-53 & 0 & 0 & 2.4 \\
C20-N2.4-53 & 20 & 0 & 2.4 \\
S20-N2.4-53 & 0 & 20 & 2.4 \\
C20-S20-53 & 20 & 20 & 0 \\
C20-S20-N2.4-53 & 20 & 20 & 2.4 \\
w/s $=87 \%$ & & & \\
Control-87 & 0 & 0 & 0 \\
C20-87 & 20 & 0 & 0 \\
S20-87 & 0 & 20 & 0 \\
N2.4-87 & 0 & 0 & 2.4 \\
C20-N2.4-87 & 20 & 0 & 2.4 \\
S20-N2.4-87 & 0 & 20 & 2.4 \\
C20-S20-87 & 20 & 20 & 0 \\
C20-S20-N2.4-87 & 20 & 20 & 2.4 \\
\hline
\end{tabular}

\subsection{Procedures}

Constituent materials were mixed in a mechanical mixer with a speed of $60 \mathrm{rpm}$. To attain homogenous dispersion of components, a specific sequence of mixing was adopted based on experimental trials. First, the soil was oven-dried according to ASTM D2216-19 [9] and then crushed with a rubber hammer until it passed sieve No.4. Approximately $17 \%$ of the mixing water was added to the dry soil while mixing for $60 \mathrm{~s}$. The cement and/or slag were added to the mixture while mixing for $30 \mathrm{~s}$. The nano-silica and the HRWRA were added to the remaining water while stirring vigorously for $45 \mathrm{~s}$ to obtain a homogenous liquid phase. Then, the liquid phase was added to the mixture and mixing continued for $120 \mathrm{~s}$ to allow for good dispersion in the mixtures. Finally, the mixtures were cast in the standard molds in three layers, given each layer 25 blows using a mechanical power hammer to obtain good compaction. For CBR samples, they were directly submerged in potable water for four days before testing following ASTM D1883-16 [13]. While the other specimens were kept in the molds for 7 days before demolding to prevent water loss and preserved in a standard curing room (maintained at a temperature of $22 \pm 2^{\circ} \mathrm{C}$ and relative humidity of more than $95 \%$ ) before testing.

\subsection{Testing}

California Bearing Ratio (CBR) and unconfined compressive strength (CS) tests were used to evaluate the treated soil. In order to measure the early-age strength of treated and untreated soil, CBR tests were carried out at soaked conditions according to ASTM D1883-16 [13]. Triplicate $152.4 \times 116.4 \mathrm{~mm}$ cylinders were cast then submerged in potable water for 4 days. The penetration depth was recorded at $2.54 \mathrm{~mm}$ using a cylindrical rod of the CBR test apparatus. Moreover, for each mixture, triplicate $100 \times 200 \mathrm{~mm}$ cylinders were cast for the compressive strength tests according to ASTM D1633 [14] which were performed at different ages (7, 28, 56, and 90 days). The compressive strength load was applied at a rate of $4 \mathrm{~mm} / \mathrm{min}$.

To better understand the influence of the binder on the original soil as well as the effect of nano-silica on the treated soil mixtures, selected specimens were analyzed using Differential Scanning Calorimetry (DSC) with an incremental heating rate of $10^{\circ} \mathrm{C} / \mathrm{min}$. The test was performed on powder samples extracted from the mixtures at different ages. The 
content of portlandite (calcium hydroxide: $\mathrm{CH}$ ) was calculated by determining the percentage drop of an ignited mass of the thermogravimetry curves at a temperature range of 400 to $450{ }^{\circ} \mathrm{C}$, then multiplying it by 4.11 (ratio of the molecular mass of portlandite to that of water) [15].

\section{Results}

\subsection{California Bearing Ratio (CBR)}

Although the unconfined compressive strength test can provide useful trends on how the additives affect the strength and stability of the treated mixtures, this test alone cannot provide complete information on the behaviour of treated soil to whether or not the soil can bear loads during the early stages of construction. Therefore, CBR was used to characterize the bearing capacity for untreated and treated mixtures and the results are listed in Table 4.

A significant drop in the bearing capacity for the untreated mixtures (Control-53 and Control-87, Table 4) was recorded due to increasing the water content compared to the untreated soil at optimum water content (Table 2). Such reduction is attributed to the decrease in the internal friction angle of clay, which consequently decreased the shear strength of the soil. In contrast, incorporating 20\% cement in the mixtures (C20-53 and C20-87) led to a notable increase in the bearing capacity compared to the control mixture without cement (Control-53 and Control-87), especially with the lower w/s (53\%). A similar trend was observed for the treated mixtures treated with slag at both low and high water contents (S20-53 and S20-87). In comparison to the control mixtures, incorporating nano-silica as a single additive (N2.4-53 or N2.4-87) had marginal influence on increasing the CBR value (1.2\% and $0.5 \%$, respectively), and these specimens yielded the lowest resistance compared to the treated mixtures with the binary or ternary binders.

Incorporating nano-silica in the binary mixtures containing cement with high water content (C20-N2.4-87) showed an increase (about 11\%) in the CBR value when compared to (C20-87). The same trend has been noticed at low water content (C20-N2.4-53) that gained an extra $24 \%$ in the CBR value when compared to (C20-53). A similar trend was observed for the mixtures containing slag and nano-silica. Comparatively, the presence of cement and slag in the mixtures (C20-S20-53 and C20-S20-87) significantly enhanced the bearing capacity (Table 4), since C20-S20-53 and C20-S20-87 yielded a CBR value of $130.7 \%$ and $77.9 \%$, respectively. Accordingly, the treated specimens made from the ternary binder of cement, slag, and nano-silica at both low and high water contents (C20-S20-N2.4-53 and C20-S20-N2.4-87) obtained the highest CBR values of $148 \%$ and $88.8 \%$, respectively. 
Table 4: CBR and unconfined compressive strength results.

\begin{tabular}{lccccc}
\hline & $\begin{array}{c}\text { California } \\
\text { Mixture ID. }\end{array}$ & \multicolumn{4}{c}{ Compressive Strength (kPa) } \\
\cline { 5 - 6 } & $\begin{array}{l}\text { Bearing Ratio, } \\
\text { CBR) }\end{array}$ & $\mathbf{7}$ days & $\mathbf{2 8}$ days & $\mathbf{5 6}$ days & 90 days \\
\hline Mixtures with 53\% water content & & & & \\
Control-53 & 0.7 & 40 & 40 & 40 & 40 \\
C20-53 & 40.3 & 690 & 880 & 900 & 910 \\
S20-53 & 9.5 & 320 & 410 & 490 & 530 \\
N2.4-53 & 1.2 & 160 & 180 & 190 & 190 \\
C20-N2.4-53 & 44.8 & 750 & 1160 & 1200 & 1210 \\
S20-N2.4-53 & 11.2 & 380 & 490 & 540 & 590 \\
C20-S20-53 & 130.7 & 1380 & 2170 & 2390 & 2470 \\
C20-S20-N2.4-53 & 148.0 & 1550 & 2340 & 2540 & 2840 \\
Mixtures with 87\% water content & & & & \\
Control-87 & 0.2 & 10 & 10 & 10 & 10 \\
C20-87 & 21.9 & 480 & 570 & 640 & 680 \\
S20-87 & 5.4 & 210 & 320 & 430 & 460 \\
N2.4-87 & 0.5 & 20 & 30 & 40 & 40 \\
C20-N2.4-87 & 27.2 & 510 & 600 & 690 & 710 \\
S20-N2.4-87 & 8.6 & 270 & 380 & 450 & 500 \\
C20-S20-87 & 77.9 & 1050 & 1690 & 1990 & 2100 \\
C20-S20-N2.4-87 & 88.8 & 1120 & 1830 & 2100 & 2210 \\
\hline
\end{tabular}

\subsection{Compressive strength}

Similar trends to that of the CBR test for the untreated specimens and treated specimens were obtained. Table 4 shows the average unconfined compressive strengths of specimens from all mixtures at different ages. Increasing the water content in the control mixtures (Control-53 and Control-87) markedly reduced the mechanical properties for the soil and these mixtures did not provide any mechanical properties (Fig. 1a). The results generally indicated that appreciable mechanical properties can be achieved with the addition of cement, slag, and nano-silica at different levels for soil containing such moisture contents.

At an early age (7 days), the compressive strength of specimens containing cement markedly increased. For instance, compared to the control specimens without cement, the compressive strengths of the single binder mixtures containing cement (C20-53 or C20-87) were 690 to $480 \mathrm{kPa}$ compared to that of the corresponding mixtures without cementitious materials, which were 40 and $10 \mathrm{kPa}$, respectively. This improvement may provide a construction platform for such weak soil and facilitate compaction of the layers. However, the strength evolution for the mixtures treated with cement diminished after 28 days. This insignificant change in compressive strength after 28 days may be attributed to the slow formation of calcium-silicate-hydrate $(\mathrm{C}-\mathrm{S}-\mathrm{H})$ and calcium-aluminate-hydrate $(\mathrm{C}-\mathrm{A}-\mathrm{H})$ forming additional skeleton with the clay particles, which took place through a diffusion-controlled process through the early hydration shells. The single binder mixture containing slag at low and high water content (S20-53 and S20-87) had an appreciable strength evolution up to 56 days, which diminished afterward conforming to its latent hydraulic nature. These trends were corroborated by 
thermogravimetry (TG) results, as discussed in the next section. Comparatively, slight improvements were recorded for the compressive strength of single mixtures containing nano-silica (N2.4-53 and N2.4-87) at 7 days and these mixtures gained the lowest (160 and $20 \mathrm{kPa}$, respectively) compressive strength compared to the corresponding single binder mixture treated with cement or slag. Also, a minimal extra improvement was recorded for these mixtures at 90 days.

The results indicated that the compressive strength of the treated specimens with cement increased with the addition of nano-silica (binary binders), especially at early ages. For example, the rate of strength development at 7 days of the nanomodified mixtures (C20-N2.4-53 and $\mathrm{C} 20-\mathrm{N} 2.4-87)$ was $9 \%$ and 6\%, respectively, higher than that of the corresponding mixture without nano-silica (C20-53 and C20-87). Also, for the long-term strength (up to 90 days), the treated mixtures containing cement and nano-silica significantly continued to gain strength at a relatively high rate compared to that of the mixture without nano-silica (Table 4). In particular, C20-N2.4-53 had a compressive strength of $1210 \mathrm{kPa}$, which was 33\% higher than that of C20-53. A comparable trend was observed for the treated mixture containing cement and slag with low water content. For example, the rate of strength development at 7 days of the C20-S20-53 mixture was almost double that of the corresponding mixture without slag (C20-53). Also, the compressive strength development of C20-S20-53 was significant after 7 days (up to $79 \%$ increase between 7 to 90 days) and achieved a high strength at 90 days (2470 kPa). The treated soil specimens made from the ternary binder of cement, slag, and nano-silica (C20-S20-N2.4-53 and C20-S20-N2.487) achieved the highest compressive strengths at both early- and late-ages, relative to the other mixtures in each $w / s$ group.
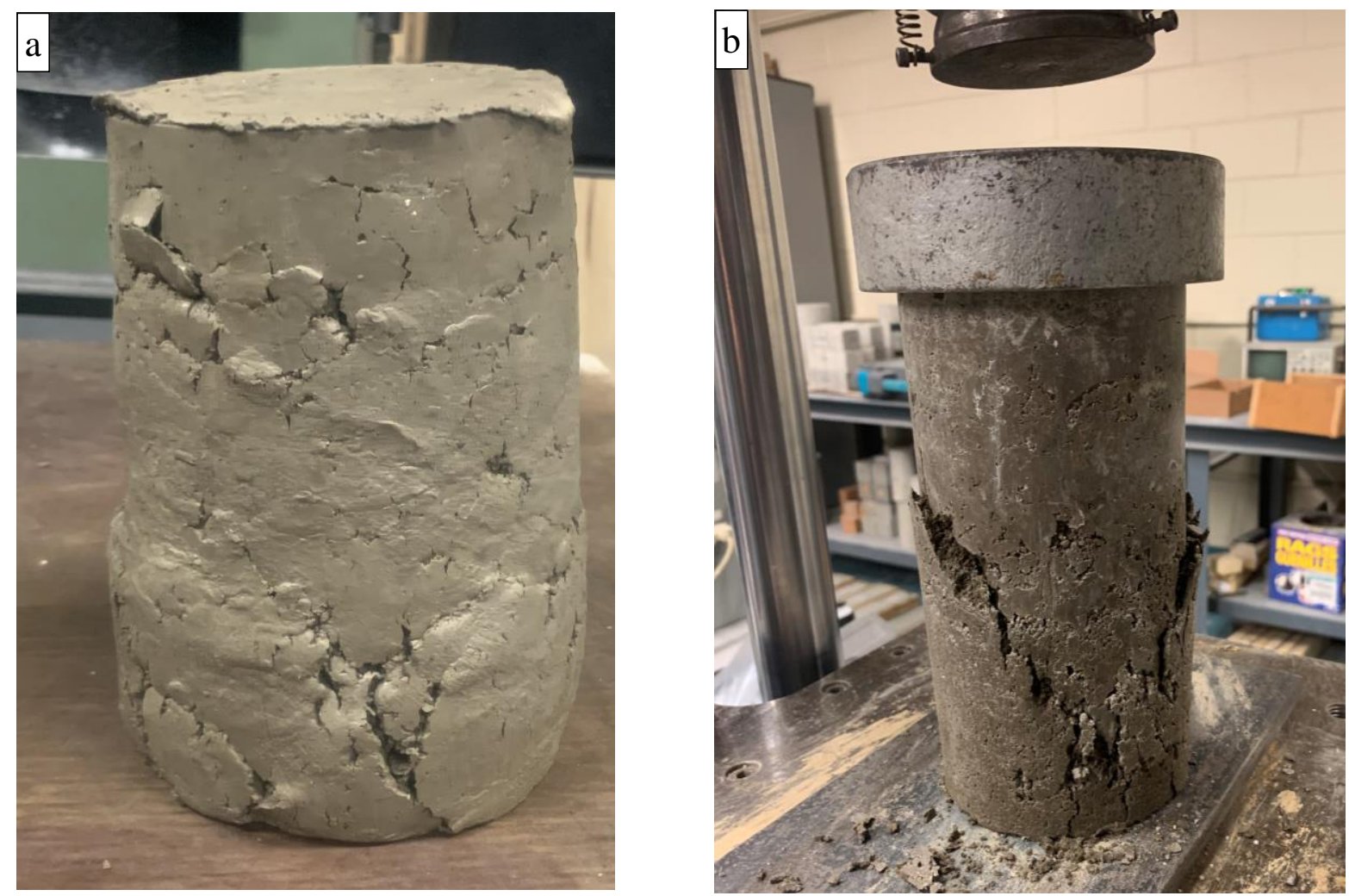

Fig. 1: Exemplar mode of failure in the compression test at 28 days for: (a) the control specimen (Control-87), and (b) ternary binder specimen containing cement, slag, and nano-silica (C20-S20-N2.4-87). 


\section{Discussion}

Increasing the water content in the virgin soil significantly affects its mechanical properties. As shown in the Results section, the control samples without treatment (Control-53 or Control-87) did not show acceptable mechanical performance. In the field, certain factors such as changes to the water table, varied environmental conditions, and climatic changes over time may cause the moisture content of the soil to increase to such levels, which is a critical scenario for the construction of pavements (wet soils).

Incorporating cement or slag in the single binder mixtures reduced the plasticity and improved the strength of the treated soil. Thermogravimetry (TG) analysis was conducted on paste samples, corresponding to the binders used in Table 2, to corroborate the bulk trends observed in the mechanical tests. The $\mathrm{CH}$ contents are listed in Table 5 at different ages to capture the evolution of hydration and pozzolanic reactions. When water is mixed with cement, hydration compounds of $\mathrm{CH}$, $\mathrm{C}-\mathrm{A}-\mathrm{H}$ and $\mathrm{C}-\mathrm{S}-\mathrm{H}$. The latter compounds act as the "glue" that provides structure in a cement-modified soil by stabilizing flocculated clay particles through the formation of clay-cement bonds. This bonding between the hydrating cement and the clay particles improves the gradation of the modified clay by forming larger aggregates from fine-grained particles. This was reflected by the development of the strength of this mixture (Table 4) and reflected by the increase $\mathrm{CH}$ contents with time (Table 5). The slag reactions are similar to cement, including hydration products and soil interactions, but are significantly slower due to its latent hydraulic nature (less lime content relative to that of cement), as indicated by the significantly lower $\mathrm{CH}$ contents (Table 5). With the existence of an alkaline activator or significant amounts of $\mathrm{CH}$, slag also shows a pozzolanic behaviour (consumption of $\mathrm{CH}$ and production of secondary C-S-H), which typically starts at later ages (beyond 28 days) [16]. In the current study, in the single slag binder, slag particles act as a filler at the early-age due to their angular shape which might produce an interlocking effect among soil particles, thus improving the mechanical properties. However, with the absence of a source of alkalinity, these binders had very slow reactivity and strength development, compared with that of counterpart mixtures made with cement. When the cementitious system was blended with equal parts of cement and slag, its reactivity was improved, as indicated by the higher mechanical properties relative to that of single system binders. For example, in mixture C20-S20-53, the higher binder content (40\%) and cement/slag blending led to combined hydration (cement) and pozzolanic (slag) reactions beyond 28 days (Table 5), which densified the matrix resulting in higher mechanical properties.

The use of $2.4 \%$ nano-silica alone acted as a filler, which enhanced the particle packing of clay particles. However, there was no considerable gain in the binding capacity, as indicated by the low mechanical properties of mixtures treated with nano-silica alone (Table 4). This was ascribed to the absence of an alkaline reactant $(\mathrm{CH})$ with nano-silica to produce secondary C-S-H (pozzolanic reaction). Comparatively, incorporating nano-silica in the binary mixtures with cement (e.g. $\mathrm{C} 20-\mathrm{N} 2.4-53$ ) led to a noticeable reduction in the $\mathrm{CH}$ content, especially at the early age, compared to that in the single mixtures (e.g. C20-53). These results are consistent with the effect of nano-silica on cementitious systems, which effectively contributes to strength development through multiple mechanisms including accelerated pozzolanic activity, the attraction of water, and filler effect [17]. This explains the improvement in mechanical properties in these mixtures as shown in the result section (Table 4). Accordingly, the $\mathrm{CH}$ contents notably decreased with time in the ternary mixtures (e.g. C20-S20N2.4-53, Table 5) containing cement, slag and nano-silica compared to single and binary mixtures. This highlights that the presence of nano-silica catalyzed the reactivity of slag and cement in the matrix, resulting in an improved level of hydration and evolution of microstructure, as reflected by the highest CBR and unconfined compressive strength of this mixture at an early age. Moreover, the continual reactivity of the ternary binder up to 90 days was attributed to the latent hydraulic and pozzolanic activity of slag with time, as reflected by the results of the later-age strength. 
Table 5: Thermogravimetry results for the portlandite contents in representative binders.

\begin{tabular}{lccccc}
\hline & \multicolumn{5}{c}{ Calcium Hydroxide (CH) \% } \\
\cline { 2 - 5 } \multicolumn{1}{c}{ Mixture ID. } & \multicolumn{5}{c}{ Curing time, days } \\
\cline { 2 - 5 } & $\mathbf{3}$ & $\mathbf{7}$ & $\mathbf{2 8}$ & $\mathbf{5 6}$ & $\mathbf{9 0}$ \\
\hline C20-53 & 7.92 & 9.13 & 11.46 & 11.91 & 12.19 \\
S20-53 & 0.70 & 1.22 & 1.38 & 1.52 & 1.51 \\
C20-N2.4-53 & 4.68 & 4.78 & 4.96 & 4.32 & 4.01 \\
S20-N2.4-53 & 0.52 & 0.75 & 1.41 & 1.38 & 1.23 \\
C20-S20-53 & 4.75 & 6.21 & 6.40 & 5.68 & 4.73 \\
C20-S20-N2.4-53 & 5.01 & 4.30 & 3.12 & 2.63 & 1.98 \\
C20-87 & 7.18 & 7.88 & 10.10 & 10.54 & 11.12 \\
S20-87 & 0.92 & 0.99 & 1.69 & 1.70 & 1.68 \\
\hline
\end{tabular}

\section{Conclusions}

Considering the materials, mixtures, and testing methods implemented in this study, the following conclusions can be drawn:

- The nano-modified mixtures with nano-silica only exhibited marginally higher mechanical properties than that of the untreated soil specimens, because of its role as a filler that enhanced particle packing of clay particles.

- Among the mixtures, a combination of cement, slag, and nano-silica (ternary binder) was the system that achieved a mutual balance among early-age (CBR and 7 days strength) and long-term (up 90 days strength) mechanical properties. The synergistic effects of cement, slag and nano-silica, multi-scale and variable reactivity system, at both low and high water contents mixtures produced the highest mechanical capacity for the treated soft clay with CBR above $85 \%$ and compressive strength of more than $2 \mathrm{MPa}$ at 28 days.

- The synoptic results of this pilot study indicate that enhancing the capacity of weak soils (soft clay) is possible in wet conditions (water contents above OMC) using equal proportions of cement and slag with a small dosage of nanosilica. Yet, field studies are needed to substantiate laboratory results, which is recommended for future research.

\section{Acknowledgement}

The authors highly appreciate the financial support from the City of Winnipeg and Natural Sciences and Engineering Research Council of Canada. The IKO Construction Materials Testing Facility at the University of Manitoba where these experiments were conducted has been instrumental to this research.

\section{References}

[1] Ahmed, Aly, and Keizo Ugai, "Environmental effects on durability of soil stabilized with recycled gypsum," Cold regions science and technology, vol. 66, no. 2-3, pp. 84-92, 2011.

[2] Prusinski, Jan R., and Sankar Bhattacharja, "Effectiveness of Portland cement and lime in stabilizing clay soils," Transportation research record, vol. 1652, no. 1, pp. 215-227, 1999.

[3] Rayón, E., Arrieta, M. P., Pasíes, T., López, J., and Jordá, J. L., "Enhancing the mechanical features of clay surfaces by the absorption of nano- $\mathrm{SiO}_{2}$ particles in aqueous media. Case of study on Bronze Age clay objects," Cement and Concrete Composites, vol. 93, pp. 107-117, 2018.

[4] Ghazy, A., and M. T. Bassuoni,"Shrinkage of Nanomodified Fly Ash Concrete as Repair Material," ACI Materials Journal, vol. 114, no. 6, 2017.

[5] CAN/CSA-A3001-13, “Cementitious Materials for Use in Concrete," Canadian Standards Association, Mississauga, ON, 2013. 
[6] ASTM International. C494/C494M-19,"Standard Specification for Chemical Admixtures for Concrete," West Conshohocken, PA, 2019.

Web. 15 Sep 2020. <https://doi-org.uml.idm.oclc.org/10.1520/C0494_C0494M-19>

[7] ASTM International. D2487-17e1,"Standard Practice for Classification of Soils for Engineering Purposes (Unified Soil Classification System)," West Conshohocken, PA, 2017.

Web. 15 Sep 2020. <https://doi-org.uml.idm.oclc.org/10.1520/D2487-17E01>

[8] ASTM International. D7928-17, "Standard Test Method for Particle-Size Distribution (Gradation) of Fine-Grained Soils Using the Sedimentation (Hydrometer) Analysis," West Conshohocken, PA, 2017.

Web. 15 Sep 2020. <https://doi-org.uml.idm.oclc.org/10.1520/D7928-17>

[9] ASTM International. D2216-19, "Standard Test Methods for Laboratory Determination of Water (Moisture) Content of Soil and Rock by Mass," West Conshohocken, PA, 2019.

Web. 15 Sep 2020. <https://doi-org.uml.idm.oclc.org/10.1520/D2216-19>

[10] ASTM International. D4318-17e1,"Standard Test Methods for Liquid Limit, Plastic Limit, and Plasticity Index of Soils," West Conshohocken, PA, 2017.

Web. 15 Sep 2020. <https://doi-org.uml.idm.oclc.org/10.1520/D4318-17E01>

[11] ASTM International. D854-14,"Standard Test Methods for Specific Gravity of Soil Solids by Water Pycnometer," West Conshohocken, PA, 2014.

Web. 15 Sep 2020. <https://doi-org.uml.idm.oclc.org/10.1520/D0854-14>

[12] ASTM International. D698-12e2,"Standard Test Methods for Laboratory Compaction CharacteristiCS of Soil Using Standard Effort (12 400 ft-lbf/ft3 (600 kN-m/m3))," West Conshohocken, PA, 2012.

Web. 15 Sep 2020. <https://doi-org.uml.idm.oclc.org/10.1520/D0698-12E02>

[13] ASTM International. D1883-16,"Standard Test Method for California Bearing Ratio (CBR) of Laboratory-Compacted Soils,” West Conshohocken, PA, 2016.

Web. 15 Sep 2020. <https://doi-org.uml.idm.oclc.org/10.1520/D1883-16>

[14] ASTM International. D1633-17,"Standard Test Methods for Compressive Strength of Molded Soil-Cement Cylinders," West Conshohocken, PA, 2017.

Web. 15 Sep 2020. <https://doi-org.uml.idm.oclc.org/10.1520/D1633-17>

[15] Yasien, Ahmed M., and Mohamed T. Bassuoni, "Nano-modified concrete at sub-zero temperatures: experimental and statistical modelling," Magazine of Concrete Research, pp. 1-20, 2019.

[16] A. M. Neville, Properties of Concrete. London, UK: Prentice Hall, 2011.

[17] Huang, Yu, and Lin Wang, "Experimental studies on nanomaterials for soil improvement: a review," Environmental Earth Sciences, vol. 75, no. 6, pp. 497, 2016. 